Joseph A. Cherian

Boston University

Anne Fremault Vila

London School of Economics

\title{
Information Trading, Volatility, and Liquidity in Option Markets
}

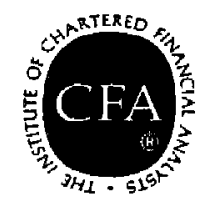

The Research Foundation of the Institute of Chartered Financial Analysts 


\section{Research Foundation Publications}

Active Currency Management

by Murali Ramaswami

Analysts' Earnings Forecast Accuracy in Japan and the United States

by Robert M. Conroy, Robert S. Harris, and Young S. Park

Bankruptcy Prediction Using Artificial Neural Systems

by Robert E. Dorsey, Robert O. Edmister, and John D. Johnson

Canadian Stocks, Bonds, Bills, and Inflation: 1950-1987

by James E. Hatch and Robert E. White

Company Performance and Measures of Value Added

by Pamela P. Peterson, CFA, and David R. Peterson

Corporate Bond Rating Drift: An Examination of Credit Quality Rating Changes Over Time

by Edward I. Altman and Duen Li Kao

Corporate Governance and Firm Performance by Jonathan M. Karpoff, M. Wayne Marr, Jr., and Morris G. Danielson

Currency Management: Concepts and Practices by Roger G. Clarke and Mark P. Kritzman, CFA

Earnings Forecasts and Share Price Reversals by Werner F.M. De Bondt

Economically Targeted and Social Investments: Investment Management and Pension Fund Performance

by M. Wayne Marr, Jr., John R. Nofsinger, and John L. Trimble

Equity Trading Costs by Hans R. Stoll

Ethics, Fairness, Efficiency, and Financial Markets by Hersh Shefrin and Meir Statman

Ethics in the Investment Profession: A Survey

by $\mathrm{E}$. Theodore Veit, CFA, and Michael R. Murphy, CFA

Ethics in the Investment Profession: An International Survey

by H. Kent Baker, CFA, E. Theodore Veit, CFA, and Michael R. Murphy, CFA

The Founders of Modern Finance: Their PrizeWinning Concepts and 1990 Nobel Lectures
Franchise Value and the Price/Earnings Ratio by Martin L. Leibowitz and Stanley Kogelman

Fundamental Considerations in Cross-Border Investment: The European View

by Bruno Solnik

Global Asset Management and Performance Attribution

by Denis S. Karnosky and Brian D. Singer, CFA

Initial Dividends and Implications for Investors

by James W. Wansley, CFA, William R. Lang, CFA, and Phillip R. Daves

Initial Public Offerings: The Role of Venture Capitalists

by Joseph T. Lim and Anthony Saunders

Interest Rate and Currency Swaps: A Tutorial by Keith C. Brown, CFA, and Donald J. Smith

Interest Rate Modeling and the Risk Premiums in Interest Rate Swaps

by Robert Brooks, CFA

Managed Futures and Their Role in Investment Pontfolios

by Don M. Chance, CFA

The Modern Role of Bond Covenants by Ileen B. Malitz

A New Perspective on Asset Allocation by Martin L. Leibowitz

Options and Futures: A Tutorial

by Roger G. Clarke

The Poison Pill Anti-Takeover Defense: The Price of Strategic Deterrence

by Robert F. Bruner

A Practitioner's Guide to Factor Models Predictable Time-Varying Components of International Asset Returns

by Bruno Solnik

The Role of Risk Tolerance in the Asset Allocation Process: A New Perspective

by W.V. Harlow III, CFA, and Keith C. Brown, CFA

Selecting Superior Securities

by Marc R. Reinganum

Time Diversification Revisited

by William Reichenstein, CFA, and Dovalee Dorsett 


\section{Information Trading, Volatility, and Liquidity in Option Markets}


(C) 1997 The Research Foundation of the Institute of Chartered Financial Analysts

All rights reserved. No part of this publication may be reproduced, stored in a retrieval system, or transmitted, in any form or by any means, electronic, mechanical, photocopying, recording, or otherwise, without the prior written permission of the copyright holder.

This publication is designed to provide accurate and authoritative information in regard to the subject matter covered. It is sold with the understanding that the publisher is not engaged in rendering legal, accounting, or other professional service. If legal advice or other expert assistance is required, the services of a competent professional should be sought.

ISBN 978-0-943205-35-9

Printed in the United States of America

January 1997

\section{Editorial Staff}

Maryann Dupes Editor

Fiona D. Russell Assistant Editor
Jaynee M. Dudley

Production Manager

Diane B. Hamshar

Typesetting/Layout 


\section{Mission}

\section{The Research Foundation's mission is}

to identify, fund, and publish research that is relevant to the AIMR Global Body of Knowledge and useful for AIMRmember investment practitioners and investors.

The Research Foundation of the Institute of Chartered Financial Analysts P.0. Box 3668

Charlottesville, Virginia 22903 U.S.A.

Telephone: 804-980-3655

Fax: 804-980-3634

E-mail: r@aimr.org

World Wide Web: http://www.aimr.org/aimr/research/research.html 


\section{Biographies of Authors}

Joseph A. Cherian teaches graduate derivatives and risk management classes at the School of Management, Boston University. Previously, he was a lecturer at the Johnson Graduate School of Management, Cornell University. He has also served as a consultant on the pricing and hedging of derivative products, specifically equity- and interest-rate-sensitive options and futures. Professor Cherian's research interests include interest rate derivatives, the use of nonlinear filtering methods in optimal portfolio selection, and issues in financial market manipulation. He is currently conducting cross-disciplinary research and education efforts in analytical finance with the Mathematics Department at Boston University. Professor Cherian holds a Ph.D. in finance from Cornell University.

Anne Fremault Vila is a research fellow in the Financial Markets Group at the London School of Economics. Prior to joining the London School of Economics, she was an assistant professor of finance at the School of Management, Boston University. Her research interests include derivative markets, security markets' structures and regulations, and international finance. Her current research focuses on the behavior of equity and option market makers. Other recent projects include a comparative study of open outcry and computerized trading mechanisms, and a study of innovation by futures exchanges. Professor Vila holds a Ph.D. in economics from the University of Pennsylvania. 


\section{Executive Summary}

Trading in financial markets involves transaction costs, some of which are exogenous (e.g., commissions and transaction taxes) and some of which are endogenous, such as the bid-ask spread. The bid-ask spread, defined as the difference between the ask price and the bid price quoted by the market maker, provides the market maker with compensation for the risk of his or her market-making activities. In a market where traders have different information, less-informed market makers face a severe adverse selection problem: Because they do not know the identity of incoming orders, they set a spread to compensate for the loss that could occur from trading with betterinformed traders.

In this respect, option markets are unique in that the information flow incorporates data about the price (or expected return) and the volatility of the underlying asset. As such, the bid-ask spread in the option market rationally reflects both information components.

The purpose of this study is twofold. First, we review a simple but realistic model of option market making that helps to explain the following:

- how information on future price volatility is incorporated in prices, and

- how liquidity in the option market is affected by information trading.

Second, we test the above-mentioned model of option market making and the validity of its predictions.

Broadly speaking, the theoretical model documents how adverse selection for price and volatility introduces a bias into transaction prices that, in turn, affects estimates of the true underlying volatility for the life of the option. This bias creates a wedge between implied volatilities and true volatilities because implied volatilities are rational estimators of true (or realized) volatilities.

The model's implications hinge on the presence of two types of information traders: those with information about future volatility, called volatility traders, and those with information about future price movements in the underlying security, called directional traders. The model predicts that if volatility traders dominate the order flow, the result is a small price effect in the underlying security but a wide implied-volatility bid-ask spread. Conversely, if directional traders dominate the order flow, the result is a large price effect in the underlying security but a narrow implied-volatility spread.

We tested these views by using a time series of option transaction prices, bid-ask quotes, and the associated implied volatilities on IBM (International Business Machines) stock. We first constructed identification tests that distinguish between volatility and directional traders. Given the partitioning of our data according to directional and volatility trading, we performed tests to verify the validity of the model's predictions. Our strongest finding is that the presence of volatility traders tends to widen the bidask spread in options but the presence of directional traders has the opposite effect. This result supports our theoretical model. A less significant finding is that directional trading has a bigger effect on subsequent stock price changes than does volatility trading. 
Most of the current methods that test for information flow in option markets were developed in the context of equity markets. These methodologies ignore the volatility component and focus instead on the price component. In contrast, our methodology provides a mechanism by which a practitioner who uses price and volume data and takes into account the volatility component can appropriately extract the information content of option prices and make reasonable inferences about market liquidity, concentration of trading, and the market's estimate of future volatility.

The implications of our tests are crucial for traders and academic researchers because more-powerful tests and specifications can only arise from more-precise economic models of the market's conditional estimate of future volatility. In this context, the knowledge accumulated from this study is useful for many aspects of practice, including trading, investing, hedging, and market making.

We wish to thank Alexander Peterhansl and Matthew Qianli Wu for outstanding research assistance. We also thank Keith C. Brown, CFA, and Robert Jarrow for helpful comments. 


\section{Information Trading, Volatility, and Liquidity in Option Markets}

Financial economists have long been interested in market efficiency-how financialmarket participants process information, which in turn improves the quality of the markets. In recent years, financial economists have turned their attention to the actual organization (or microstructure) and regulation of financial markets and the relationship of these markets with informational efficiency. The unprecedented wave of innovations in products and information technology has further brought the issues of market efficiency and competition between different market systems to the forefront of academic research. In this study, we analyze liquidity and informational efficiency in the context of option markets-topics that are particularly challenging to practitioners and academics because the information flow incorporates price and volatility information.

This study describes a simple but realistic model of option market making that shows how information on future price volatility is incorporated in prices and how liquidity in option markets is affected by information trading. In this context, we explain how the bid-ask spread introduces a bias into transaction prices that affects estimates of the true underlying volatility, based on implied volatilities. Indeed, the documented inefficiency of implied volatility as an estimator of true volatility (see Canina and Figlewski 1993 and Lamoureux and Lastrapes 1993) may reflect market makers' adjustments for the adverse selection with which they are confronted. The model can also be used to make predictions about the size and the position of the bid-ask spread, which may help to understand empirical irregularities, such as the overreactions phenomenon documented by Stein (1989).

Our primary objective in this study is to test our model of market making and the validity of its predictions. To do so, we first review the literature associated with the current study, which is an edited version of the review found in Cherian (1993, Chapter 1). Next, we review the theoretical model on which the empirical tests are based, link the theory to testable implications, and discuss its practical implications. Finally, we present the data and the empirical methodology and report the empirical results.

\section{Literature Review}

In a perfect and complete market, an option is a redundant security whose price is determined by no-arbitrage conditions. Using this arbitrage pricing technique, Black and Scholes (1973) and Merton (1973) valued the option as a function of the current price of the underlying security, the volatility of the security's returns, the strike price, the risk-free rate, and the time to maturity. The four main assumptions underlying the model are as follows:

- The security price at any future time is lognormally distributed with constant instantaneous volatility over the life of the option.

- The market for traded assets is frictionless, and trading is continuous.

- The instantaneous risk-free rate is constant over the life of the option. 
- The underlying security pays no dividends.

The authors then showed that under these assumptions, markets are complete and an option can be replicated by a dynamic position in its underlying security and bonds. Hence, any price deviation from this replicating portfolio's value would generate riskless arbitrage profits. Therefore, in the absence of arbitrage opportunities, the replicating portfolio's value gives a unique option price, commonly known as the Black-Scholes-Merton value.

Subsequent academic studies have shown that the Black-Scholes-Merton model is robust to the relaxation of a variety of these assumptions. Unfortunately, the formula is not robust to all perturbations to its underlying structure. Researchers contend that stochastic volatilities and/or trading frictions usually yield an incomplete market, which prevents the construction of a perfect hedge (see Eisenberg and Jarrow 1994). In light of these observations, the assumption underlying the Black-Scholes-Merton pricing model that the stock price volatility over the remaining life of the option is known and a constant must be examined further. In reality, future volatility is unknown and must be estimated; more importantly, it varies over time. Hence, one would not expect the Black-Scholes-Merton model to work in practice because volatility is a stochastic process and the risk factor induced is not spanned by the two primary securities.

Nevertheless, the Black-Scholes-Merton model has become something of an industry standard for pricing options on a variety of instruments. In two recent papers, Cherian (1996) and Cherian and Jarrow (1996) determined theoretically that the BlackScholes-Merton option-pricing model can arise merely from self-perpetuating beliefs that it is the correct pricing formula, even when markets are incomplete. ${ }^{1}$ In other words, given that traders enter markets using the Black-Scholes-Merton model, their conjectured pricing rule is confirmed in a Black-Scholes-Merton equilibrium.

Because model misspecification is a serious concern for investment and risk managers, a closer look at the traditional methods used for pricing and hedging options and the implications of misspecification for the performance of strategies based on misspecified option-pricing models is warranted. ${ }^{2}$ Two types of errors arise from model misspecification: pricing error and hedging error. Without question, if an investment manager uses an incorrect model to indicate the "fair price" to pay for an option, the price will not compensate him or her for the risk he or she bears as a result of using a misspecified model. Hedging errors, on the other hand, will be apparent when the sensitivity of option values to changes in underlying parameter values is not correlated with the hedge ratios that result from the misspecified model.

In order to reduce the effects of model misspecification on hedging errors, one can construct appropriately adjusted hedge ratios that account for the causes of the misspecification. And to reduce the effects of model misspecification on pricing errors, one can use implied volatilities rather than statistical volatilities when calculating option values. ${ }^{3}$ In this respect, a clear understanding of the economic model that explains how information on future volatilities is incorporated into implied volatilities is necessary. Model risk, political risk, and adverse-selection risk are but a few of the risks rationally reflected in implied volatility. The market's assessment of these risks is, therefore, part

\footnotetext{
${ }^{1}$ See Azariadis (1981) for a treatise on self-fulfilling prophecies in economic situations (i.e., prices move because they are expected to, not because fundamentals dictate). Azariadis's research is in the spirit of the sunspot equilibrium literature of Shell (1977) and Cass and Shell (1983), who formally modeled the interdependence of "rational" beliefs leading to self-justifying equilibriums.

${ }^{2}$ For a discussion of model misspecification, see Jarrow and Turnbull (1996, Chapter 10).

${ }^{3}$ Implied volatility is the volatility that sets the market price of the option to the model value.
} 
of the specification of implied volatilities that must be extracted for its information content. Hence, an understanding of implied volatilities through a reasonable economic model is paramount for investment and risk managers.

In this context, Cherian (1996) and Cherian and Jarrow (1996) provide a reasonable economic model of how information on future volatilities is incorporated into implied volatilities. Because of the asymmetric nature of an option's payoff, its price depends on beliefs regarding the true volatility of the underlying security over the remaining life of the option. Consequently, the volatility implied by the option's market price should rationally reflect the "market estimate" of future volatility, given its information set. These authors formulated a market structure in which volatility estimates are derived under the condition that traders in equilibrium are rationally using the Black-ScholesMerton model as their pricing rule. Their model can be viewed as an informational model of volatility discovery and formation. It incorporates the pricing of volatility risk that results from adverse selection facing the market maker when setting option prices. ${ }^{4}$ A summary of the Cherian (1996) and Cherian and Jarrow (1996) model is provided later in the discussion of our theoretical model.

Related Theoretical Models: A Review. Given the focus of our research, we have subdivided our review of the theoretical literature along two lines-one focusing on the structure and dynamics of option markets, including frictions, imperfections, or incompleteness, and the other on identical issues in primary markets. The term "market microstructure" is reserved for models that explicitly account for the internal mechanism of financial markets, the microeconomic interaction between traders, and the trading process itself. An underlying feature in such asset-pricing models is that the standard competitive Walrasian equilibrium argument of financial economics does not apply. The interested reader is referred to the manuscript by O'Hara (1995) for an excellent academic discourse on market microstructure.

- Market microstructure-stock markets. The general approach in informationbased models of asset pricing is that a risk-neutral competitive market maker addresses the order flow imbalance in stocks. The risk neutrality and perfect competition assumptions lead to the market maker setting prices such that zero profits appear on average. This result leads to a semistrong-form informational efficiency condition for asset prices because they are set at the mean of the asset's true value, given the prevailing information set of the market maker. The market maker, in addition, faces an adverse-selection problem because a nontrivial number of informed traders are able to hide their trades among the noise traders' orders; identities among floor participants are diffused. Price and order flow are usually the variables determined in equilibrium.

Kyle (1985) used in his analysis noise traders-risk-neutral monopolistic insiders who take into account the impact of their trades on equilibrium prices-and risk-neutral market makers, who aggregate the floor orders and rationally set prices conditional on the order flow imbalance and their information set. Then, because risk neutrality and perfect competition result in informationaily perfect, revealing equilibriums, Kyle introduced informed traders, who trade strategically. In the unique linear equilibrium that results, prices are a linear function of the aggregate order flow. The informed trader optimally submits orders that increase with noise trading because noise helps diffuse the information content of the trades.

\footnotetext{
${ }^{4}$ For a theoretical model of asset pricing that incorporates the effects of political risk on option prices, see Cherian and Perotti (1996).
} 
Glosten and Milgrom (1985) modeled individual orders of unit size that arrive at the market maker's desk in a sequential manner. Under the assumption of risk neutrality and a Bayesian market maker (i.e., one who probabilistically conditions trades on the likelihood of the trade being informed or uninformed), Glosten and Milgrom found that the presence of informed traders leads to a strictly positive bid-ask spread. The bid and ask prices straddle the unconditional estimate of asset value, with the spread increasing with the precision of the insiders' information, the ratio of informed to uninformed traders, and the elasticity of noise trading. These results also extend to the Cherian (1996) and Cherian and Jarrow (1996) option model under certain conditions. A drawback to the Glosten and Milgrom model, however, is that informed traders lack the strategic spatial and intertemporal trading flexibility that is available in the Kyle model.

Easley and O'Hara (1987) compensated for this lack of flexibility by allowing the informed traders to choose between small market orders and large block orders. In addition, the authors assume that from the rest of the market's perspective, the existence of private information is not certain. Depending on market conditions, the market is either in a separating or a pooling equilibrium, with large trades being made at less favorable prices. In a separating equilibrium, the informed trader optimally trades large blocks; in a pooling equilibrium, the informed trader mixes between small and large orders. Easley and O'Hara also showed that because of the dual uncertainty in the model, both the size and sequence of trades are important in determining the sample path of the price process. For example, when the market is in a separating equilibrium, uncertainty about an information event occurring can cause price pressures to result from block trades (i.e., price reversals occur as a result of large trades). The structures described in Glosten and Milgrom (1985) and Easley and O'Hara (1987) are appealing because they reasonably approximate existing U.S. financial securities exchanges, which have either specialists or multiple dealers who match intertemporal buy and sell orders.

- Market microstructure-option markets. Because option payoffs are not only state contingent but also asymmetric, the added dimension of uncertainty when pricing options makes modeling the microstructure of option markets difficult. Furthermore, the risk factors induced by added sources of uncertainty may be correlated in a nontrivial way over time.

Attempts at modeling the microstructure of option markets include Biais and Hillion's (1990) pioneering study of price formation in an option market with two call options of different strikes under two states of nature. In their model, a perfectly competitive Bayesian market maker who faces the possibility of trading with an informed trader with quantity constraints uses risk- and information-adjusted posterior probabilities when calculating bid and ask prices. An interesting result is that when market makers are risk neutral, the insider optimally trades in-the-money options. This finding is contrary to the predictions of traditional option-pricing theory, which claims that because of the high degree of leverage provided by out-of-the-money options, insiders should concentrate their trades in these instruments. The rationale for the latter strategy is that insiders obtain maximal "bang for the buck" by trading on their own private information.

John, Koticha, and Subrahmanyam (1991) modeled the mixed strategy equilibrium that emerges when a trader who is informed of future stock price movements trades concurrently in the option market and the underlying market in order to camouflage his or her trades (equivalently, information) from the rest of the market. In this case, the insider balances the benefit of trading in option markets that results from the leverage effect with the corresponding cost that the insider's trade introduces through increased adverse selection. The analysis incorporated two types of noise traders and 
margin requirements for the informed trader in the option and underlying markets. The authors found that stocks with listed options have high liquidity and low realized volatility and that listed options reduce the information content of stock prices. ${ }^{5}$ These are intuitive results based on the assumptions of the model. Because the informed trader spreads trades between primary and derivative markets, the stock market is less informationally efficient and faces less-severe adverse-selection costs than in the case without a derivative market.

Neither Biais and Hillion nor John et al. model the dynamic informational linkages between primary and derivative markets. Back (1993) takes a step in this direction. In an extension of the continuous-time Kyle model, he introduced an option that is hypothetically redundant, in the sense that one could duplicate the cash flows to the option using the stock and a riskless asset. When the option is introduced as a traded asset, however, information flows through imperfectly correlated order flows in the stock and the option dynamically feeds back into the stock price process, causing volatilities to be stochastic. In other words, the introduction of the option as a traded asset into a model of adverse selection causes the option order flow to cease being informationally redundant with respect to the stock order flow, resulting in the stock and option prices being locally imperfectly correlated. This imperfect correlation renders the market incomplete, and a perfect hedge can no longer be formed.

Related Empirical Models: A Review. The empirical literature focuses on the joint hypothesis that implied volatilities are accurate forecasts of future volatilities and that option markets are informationally efficient. In the process of testing this joint hypothesis, the market's option-pricing model must be correctly specified, which is necessary in order to estimate the volatility from the market price of the option. Note that given the pricing model, any biases introduced while estimating volatilities from market prices could affect the interpretation of the test results. We first review in detail two important empirical papers related to the implications of our model. The subsequent reviews in this section are less detail oriented.

Using data on equity options, Lamoureux and Lastrapes (1993) investigated whether market estimates of volatility, as reflected in implied volatility, are good forecasts, conditional on the marketwide information set available at the time the estimates are made, of future volatility. The authors used Hull and White's (1987) option-pricing model with stochastic volatility to calculate implied volatilities from market prices of options. In order to remove any variance-estimate biases resulting from nonlinearities inherent in the option-pricing model, Lamoureux and Lastrapes examined only at-the-money options, which analytically (see Feinstein 1995) and through simulations (see Lamoureux and Lastrapes) are shown to be approximately linear in time-averaged volatility.

The two main results of the Lamoureux and Lastrapes tests were that implied volatility generally underpredicts realized volatility of stock returns and that the market does not incorporate relevant information contained in forecasts of volatility from past stock returns. The first result could be attributed either to biases introduced from not incorporating transaction costs in the pricing model or to option traders overreacting to volatility shocks. Lamoureux and Lastrapes, although not discounting the importance of transaction costs, suggest that because the market is reasonably efficient for the more-liquid equity options, the data on implied volatilities might be indicating that volatility risk is, in fact, a priced risk, a phenomenon not captured in the Hull and White model. This conjecture

${ }^{5}$ The first two results are consistent with an increase in market quality in the sense of Black (1971), and the third result reduces the quality of the market. 
is modeled later in the discussion of our theoretical model.

In related research, Canina and Figlewski (1993) examined the informational efficiency of implied volatility as a forecast of realized volatility by using data on S\&P 100 Index options. This study differs from the Lamoureux and Lastrapes investigation in methodology and in the options data set. Canina and Figlewski were interested in finding out whether the market is rationally and efficiently using publicly available information when forming volatility forecasts, as reflected through implied volatility. Canina and Figlewski assumed that the forecaster and the market agree on the optionpricing model (the binomial option-pricing model in this case), that implied volatility is an informationally rational forecast of true volatility, and that no major measurement errors exist that will bias the empirical results. The third point is especially important because volatility is a time-varying parameter and, as such, the time series of implied volatility is a forecast of volatilities that have different and/or overlapping horizons. Hence, taking a cross-sectional weighted average of implied volatilities from different options on the same stock with different horizons does more than diversify away "wellbehaved" white noise; it may introduce biases that are detrimental to the informativeness of the tests.

The Canina and Figlewski test results indicate that for all subsamples, the hypothesis that implied volatility is an accurate forecast of true volatility can be rejected. In fact, using a method called "encompassing regression testing," Canina and Figlewski found that implied volatilities do not incorporate valuable information available in historical volatility estimates, a result that is consistent with the Lamoureux and Lastrapes result. In other words, historical estimates contain information over and above what implied volatilities contain about realized volatility.

Canina and Figlewski interpreted the results as implying that volatilities capture everything that the option-pricing model cannot. In other words, model misspecification risks are associated with the binomial option-pricing framework. For example, gamma risk (inability to hedge continuously), volatility risk, and transaction costs are but some examples of risks not priced in the binomial framework that could have some explanatory power for the observed results. An implication of this finding is that implied volatilities may contain information on how models of option-pricing theory should be refined. Finally, to get a good forecast of realized volatility, Canina and Figlewski suggest that one should perhaps look at historical estimates of volatility.

Stein (1989) assumes that the true volatility process follows a mean-reverting diffusion process and that implied volatility is the time-averaged expectation of this process over the life of the option. Based on these assumptions, he derived a theoretical relationship between nearer-maturity and further-maturity implied volatilities, which forms the basis of his tests. Using the binomial model to invert volatilities from option prices, Stein documented an "overreactions" result in the term structure of implied volatilities. By assuming that true volatility is mean reverting, he found that implied volatility on further-maturity options exceeds the theoretical restriction mean reversion places on it. He attributed this result to traders overreacting to nearer-term volatility shocks.

Rubinstein (1985) conducted nonparametric tests on the joint hypothesis that option markets are efficient and that option market prices and Black-Scholes-Merton values do not exhibit systematic biases. He tested his hypothesis on matched pairs of options data by using options on the Chicago Board Options Exchange (CBOE) and some rigorous data-screening procedures. The term "matched" refers to controlling for all other parameters while comparing the effect of the parameter of interest-in this case, either time to maturity or strike price-on implied volatility.

From our perspective, what makes the Rubinstein study interesting is that the joint 
hypothesis, when measured in terms of implied volatility, is violated for time-to-maturity and strike-price tests. For example, out-of-the-money options have significantly decreasing implied volatility with respect to time to maturity; near-maturity options have implied volatilities that increase with how deep in the money or out of the money the option is. Rubinstein made a comparative study to see whether any extant alternative optionpricing model could systematically explain these biases. ${ }^{6}$ His answer was negative. Furthermore, he suggested that these systematic biases could probably be correlated to systematic factors in the economy.

In summary, all the empirical papers cited make the common claim that a need exists for a robust extension of the traditional option-pricing formula that should account for the observed systematic biases in option-implied volatilities. In the next section, we provide a simple theoretical model that partly addresses this requirement.

\section{The Theoretical Model}

Our theoretical model draws primarily from the work of Cherian (1996) and Cherian and Jarrow (1996). We consider a two-period economy with two trading dates, denoted by $t=0$ and $t=1$, and a constant, continuously compounded interest rate, $r$. Trading are a stock, a riskless bond, and a European call option on a risky security (or underlying stock) with a fixed strike price, $K$, and expiration date, $T$. Markets, by construction, are incomplete with respect to the stock and bond alone. As such, the Black-Scholes-Merton model does not formally apply as in the original arbitrage-free context because a perfect hedge cannot be formed.

Two classes of agents trade options: risk-neutral, perfectly competitive market makers, who passively absorb the order flow imbalance, and a continuum, indexed by the interval $[0,1]$, of variously informed, risk-neutral traders. The latter traders are further subdivided into three types: (1) the fraction $0<\alpha<1$ of volatility traders, or $\sigma$ traders, (2) the fraction $0<\beta<1$ of directional traders, or $\mu$-traders, and (3) the fraction $0<1-\alpha-\beta<1$ of liquidity traders, or hedgers. The volatility traders, or $\sigma$-traders, have information on the future volatility of the stock; the directional traders, or $\mu$-traders, have information relating to the mean return of the stock; and the hedgers are uninformed traders with price-inelastic demand functions. A precise description of each trader's beliefs and information structures follows.

Traders arrive sequentially and anonymously at the trading post to submit their demands to the market maker. Assume that only one trader is accommodated each period by the market maker. The market structure and trading mechanism used in this study, therefore, resemble the sequential trade models of Glosten and Milgrom and of Easley and O'Hara, described previously.

In the spirit of traditional option-pricing models, the stock price evolution over time is taken as a given. The simplicity of the analysis and the richness of the model justifies this partial equilibrium setup. At the initial trading date $t=0$, the stock price, $S$, is observed by all market participants. This initial stock price can be interpreted as the last recorded transaction price in the equity market. Market participants have mutually absolute continuous beliefs about the stock price evolution, thus "agreeing" on the possible outcomes for the stock's price at the next trading date, $t=1$, and at the option expiration date, $t=T$. Figure 1 illustrates these beliefs and the associated stock price tree. A description follows.

At trading date $t=1$, three possible stock prices exist: $S(1+u), S$, and $S(1+d)$, where

\footnotetext{
${ }^{6}$ The option pricing models prior to $1985 \mathrm{did}$ not include stochastic volatilities.
} 
Figure 1. Stock Price and Volatility Tree with Prior Beliefs

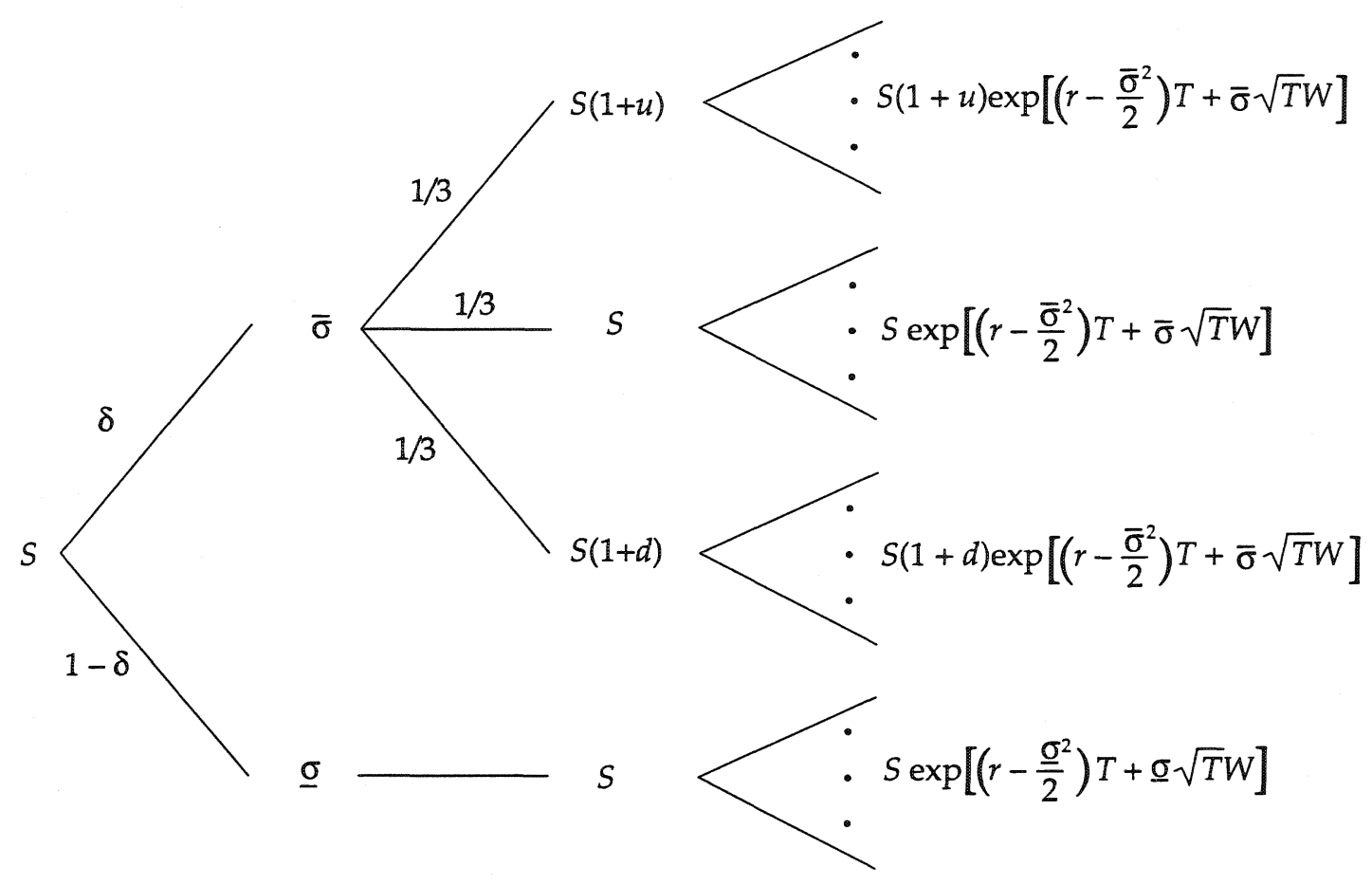

Time 0

1

$T$

Note: The prior beliefs on volatility are a two-point distribution, $[\delta, 1-\delta]$ on the possible outcomes $[\bar{\sigma}, \sigma]$, whereas the stock price outcomes when $\bar{\sigma}$ occurs are assumed to be equiprobable. $W$ is normally distributed with Mean 0 and Variance $1 ;(1+$ $u)>e^{r}>1>(1+d)$, and $\bar{\sigma}>\sigma$.

$(1+u)>e^{r}>1>(1+d)$. In addition, a third parameter is introduced: the volatility of the stock's return over the remaining life of the option, that is, from Time $t=1$ to $T$. The possible values for this parameter are $\bar{\sigma}$ and $\underline{\sigma}$, where $\bar{\sigma}>\underline{\sigma}$. The state space is restricted to four possible outcomes: $[S(1+u), \bar{\sigma}],[S, \bar{\sigma}],[S(1+d), \bar{\sigma}]$, or $[S, \underline{\sigma}]$. The choice of States 1 through 4 corresponds to a high-volatility market at Time 1 with changing stock prices (high, flat, or low). The final state corresponds to a low-volatility flat market.

The prior beliefs for the likelihoods of these four states are given along the branches of the tree. The prior beliefs on asset volatility are captured by a two-point distribution, $[\delta, 1-\delta]$, on the value of the stock's return volatility, $[\bar{\sigma}, \underline{\sigma}]$. Given a high-volatility market, $S(1+u), S$, and $S(1+d)$ are assumed to be equally likely outcomes. This assumption is without loss of generality because the magnitudes of the jumps $u$ and $d$ are unrestricted. Finally, at time $T$, the stock price is lognormally distributed with parameters (stock price and volatility) determined at Time 1.

Therefore, the market, by construction, is incomplete. Because four outcomes are possible at Time 1, the call option market is incomplete in the stock and bond over the first trading period. Also, because a continuum of stock prices is possible at time $T$ and only discrete trading is allowed, the market is also incomplete over the second trading period. As such, arbitrage arguments alone cannot justify the use of the Black-ScholesMerton model.

To ensure that the stock is fairly priced to uninformed participants, we impose the following restriction. The expected return on the stock given current marketwide information equals the risk-free return. More formally, at Time 0 , 


$$
S=e^{-r} E\left(S_{1}\right)
$$

and at Time 1 ,

$$
S_{1}=e^{-r(T-1)} E\left(S_{T} \mid S_{1}, \sigma\right),
$$

where

$$
\left(S_{1}, \sigma\right) \in[(S(1+u), \bar{\sigma}),(S, \bar{\sigma}),(S(1+d), \bar{\sigma}),(S, \underline{\sigma})] .
$$

The informed traders, therefore, will see trading opportunities in both the stock and the option market. Given the partial equilibrium nature of the model, only the call option market equilibrium is characterized. The trading mechanism at each date is one in which the market maker sets option bid and ask prices contingent on the order submitted. To abstract from the informational content of trade size, we consider traders who buy or sell a unit of the call option at each date.

The information structures are as follows. At Time 1, the state of nature

$$
\left(S_{1}, \sigma\right) \in[(S(1+u), \bar{\sigma}),(S, \bar{\sigma}),(S(1+d), \bar{\sigma}),(S, \underline{\sigma})]
$$

is revealed to all market participants. Hence, all strategic trading and private information revelation, if any, takes place at Time 0 . Because no differential information exists at Time 1 , the call option's market price at Time 1 can easily be determined using risk-neutral valuation. In fact, the choice of distribution for the terminal stock price reduces the option price to its Black-Scholes-Merton value at $\left(S_{1}, \sigma\right)$. This choice is not essential for the following analysis.

The Time 0 information structures and action choices for the various market participants are summarized in Figure 2. This structure is an extensive form game with incomplete information standard in the market microstructure literature. The game has four stages at Time 0 .

Stage 1 . The market maker sets the bid and ask prices-given that he or she observes the last transacted stock price $S$ and conditional on the order submitted (market order to sell in the case of the bid price and market order to buy in the case of the ask price).

- Stage 2. Nature chooses, according to the probabilities provided, the states of nature

$$
\left(S_{1}, \sigma\right) \in[(S(1+u), \bar{\sigma}),(S, \bar{\sigma}),(S(1+d), \bar{\sigma}),(S, \sigma)] .
$$

The $\sigma$-traders observe $\bar{\sigma}$ and $\sigma$. They cannot, however, distinguish whether $S(1+u)$, $S$, or $S(1+d)$ occurs when volatility is high. In the case when volatility is low, they know that $S$ occurs. The $\mu$-traders observe $S(1+u), S$, or $S(1+d)$. In the case of $S$, they do not know if $\bar{\sigma}$ or $\underline{\sigma}$ occurs. Otherwise, they know that volatility is high.

The information structure is consistent with $\sigma$-traders who know the volatilities but not the direction of stock price movements. Conversely, the $\mu$-traders know the direction of stock price movements but not the volatilities.

- Stage 3. Nature chooses who trades according to the probabilities provided.

- Stage 4. At their decision nodes, the $\sigma$ - and $\mu$-traders see the bid and ask prices and decide to either buy, sell, or refrain from trading. The hedgers are equally likely to buy or sell the call option irrespective of advertised prices.

Finally, at Time 1 , the state $\left(S_{1}, \sigma\right)$ is revealed and the rest of Figure 1 applies.

The equilibrium characterization in this economy is similar to the one used in the 
Figure 2. Information Structures and Action Choices of Various Market Participants at Time 0

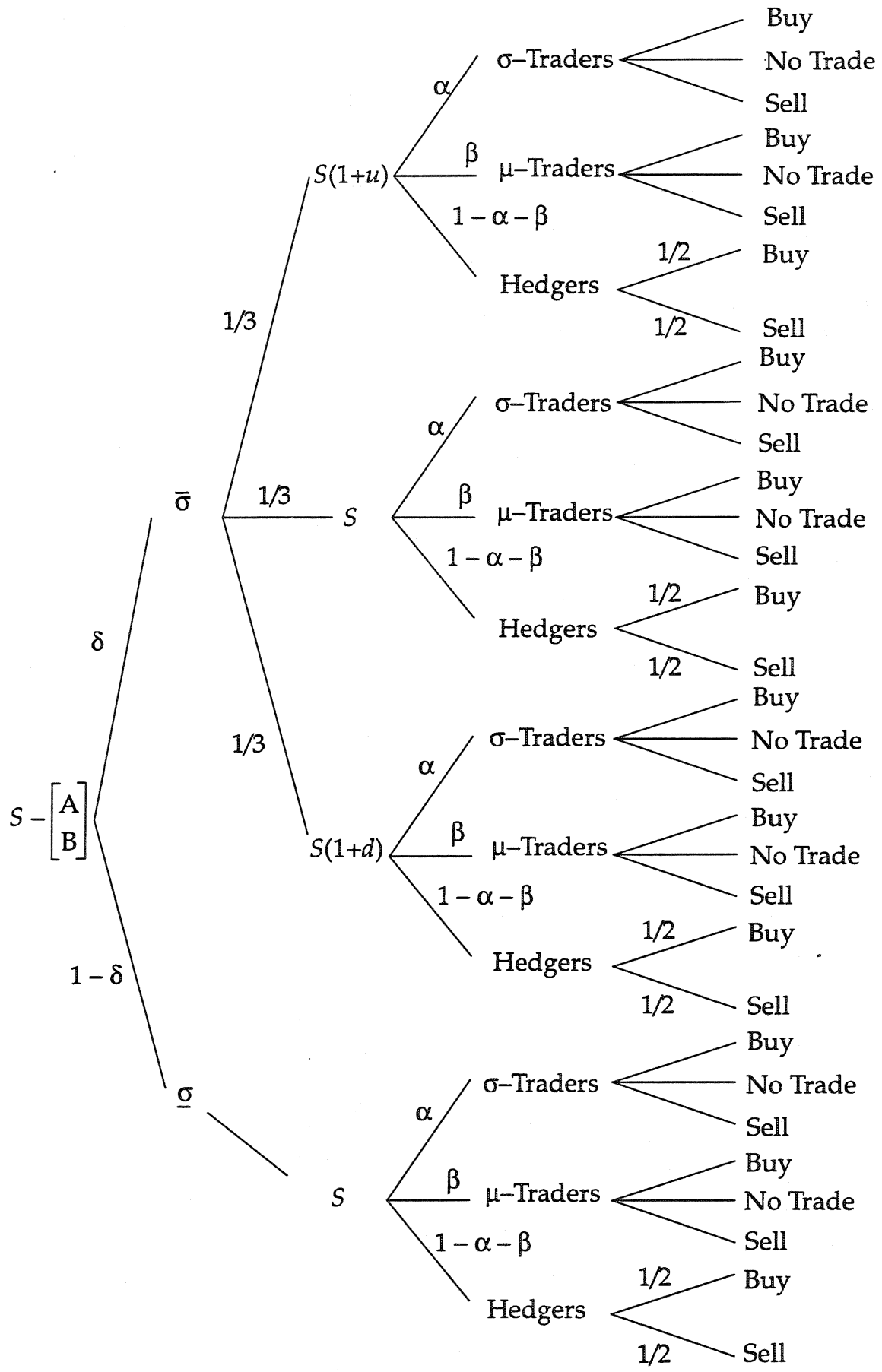

market microstructure literature. The details of the equilibrium are discussed in depth in Cherian (1996) and Cherian and Jarrow (1996). For brevity's sake, we provide only an overview of the analysis. At Time 1 , because uncertainty about $\left(S_{1}, \sigma\right)$ is resolved and all traders are risk neutral, the call option is given by its discounted expected value at 
its maturity date, $T^{7}$ The lognormal distribution of the terminal stock price results in the Time 1 equilibrium call price being its Black-Scholes-Merton value, given the statedependent stock price and volatility. Denoting $C_{1}\left(S_{1}, \sigma\right)$ as the call price at Time 1 ,

$$
C_{1}\left(S_{1}, \sigma\right)=B S\left(S_{1}, \sigma\right)
$$

where

$$
\begin{aligned}
B S\left(S_{1}, \sigma\right) & =S_{1} N\left[h\left(S_{1}, \sigma\right)\right]-K e^{-r T} N\left[h\left(S_{1}, \sigma\right)-\sigma \sqrt{T}\right] \\
N(.) & =\text { the cumulative distribution function of the standard normal random variable, } \\
h\left(S_{1}, \sigma\right) & =\frac{\log \left(S_{1} / \mathrm{Ke}^{-r T}\right)}{\sigma \sqrt{T}}+\frac{1}{2} \sigma \sqrt{T}, \text { and } \\
\left(S_{1}, \sigma\right) & \in[(S(1+u), \bar{\sigma}),(S, \bar{\sigma}),(S(1+d), \bar{\sigma}),(S, \underline{\sigma})] .
\end{aligned}
$$

Given the equilibrium call prices at Time 1 , we can derive the call market equilibrium at Time 0 . The set of optimal strategies for the three strategic traders (i.e., the market maker and the two differentially informed traders) must be derived first. The informed traders' optimality conditions, given that they observe the ask price, $A$, and the bid price, $B$, are

- buy if and only if $A<e^{-r} E\left[C_{1}\left(S_{1}, \sigma\right) \mid\right.$ Information set $]$,

- no trade if and only if $B \leq e^{-\gamma} E\left[C_{1}\left(S_{1}, \sigma\right)\right.$ IInformation set $] \leq A$, and

- sell if and only if $e^{r} E\left[C_{1}\left(S_{1}, \sigma\right) \mid\right.$ Information set $]<B$.

Hence, the informed $\sigma$-trader and $\mu$-trader will buy if their valuations exceed the ask price, sell if their valuations are less than the bid price, and refrain from trading otherwise. The hedgers, by virtue of their price-inelastic demand functions, are not strategic and trade regardless of the actions of the informed traders.

Market makers, having knowledge of the game-tree structure, form posterior beliefs about the states $\left(S_{1}, \sigma\right)$ based on the order submitted and rational conjectures about who is trading. Given that market makers are risk neutral and perfectly competitive, they set bid and ask prices as follows:

$$
\begin{aligned}
& A=e^{-r} E\left[C_{1}\left(S_{1}, \sigma\right) \mid \mathrm{Buy}\right] \\
& B=e^{-r} E\left[C_{1}\left(S_{1}, \sigma\right) \mid \text { Sell }\right] .
\end{aligned}
$$

Because $C_{1}\left(S_{1}, \sigma\right)$ are Black-Scholes-Merton values, the bid and ask prices are weighted averages of Black-Scholes-Merton values.

Six possible market-maker scenarios explain who buys and sells in the various states. These possibilities are provided in Table 1. Cherian and Jarrow (1996) argued that Case 5 is the most interesting and likely equilibrium scenario and occurs when the number of hedgers trading in the market is small compared with the number of $\mu$ traders. In the Case 5 equilibrium, the volatility trader buys when observing $\bar{\sigma}$ and sells when observing $\underline{\sigma}$; the $\mu$-trader buys when observing $S(1+u)$, sells when observing $S(1+d)$, and does not trade when observing $S$. The $\mu$-trader's trading strategy can be explained primarily because adverse selection is high (which results in large values for

${ }^{7}$ One can assume that $r$ is small enough and $T$ large enough that $r(T-1) \approx r T$. In other words, the trading dates are close enough that time decay issues do not dominate the price setting process. 
Table 1. Equilibrium Trading Conjectures of the Market Maker, by States of Nature

\begin{tabular}{|c|c|c|c|c|}
\hline & $S(1+u), \bar{\sigma}$ & $S, \bar{\sigma}$ & $S(1+d), \bar{\sigma}$ & $S, \underline{\sigma}$ \\
\hline$\sigma$-Traders & & & & Sell \\
\hline Case 1 & Buy & Buy & Buy & \\
\hline$\mu$-Traders & & & & Buy \\
\hline Case 1 & Buy & Buy & Buy & No trade \\
\hline Case 2 & Buy & No trade & No trade & Sell \\
\hline Case 3 & Buy & Sell & Sell & Buy \\
\hline Case 4 & Buy & Buy & No trade & No trade \\
\hline Case 5 & Buy & No trade & Sell & Buy \\
\hline Case 6 & Buy & Buy & Sell & \\
\hline
\end{tabular}

$A$ and small values for $B$ ), thus ruling out participation in flat markets-that is, when $S$ is observed. Based on the above, the subsequent analysis focuses only on Case 5. Theanalysis for the other five cases can be carried out in a similar fashion.

In order to study an information-based model of implied volatilities and because of nonlinearities, one must remove the deterministic or parametric biases that the BlackScholes-Merton model sets forth. Because characterizing these biases is easy and the objective of the empirical study is to look at the informational content of implied volatilities, ignoring such biases is the preferred approach. In this spirit, Feinstein (1995) showed that at-the-money Black-Scholes-Merton option prices are approximately linear in volatility for values very close to zero. Hence, for at-the-money options, the following lemma is obtained.

Lemma: Implied volatilities are rational forecasts of true volatility. For at-the-money options, the equilibrium pair shown in Equations 1 and 2 can be replaced by the following:

$$
\begin{aligned}
& a \approx e^{-r} E(\tilde{\sigma} \mid \text { Buy }) \\
& b \approx e^{-r} E(\tilde{\sigma} \mid \text { Sell }),
\end{aligned}
$$

where $a$ and $b$ are the ask and bid implied volatilities, respectively, that set the option ask and bid prices equal to Black-Scholes-Merton prices.

The immediate implication is that the option market maker can be equivalently viewed as setting ask and bid volatilities rationally in light of the order flow. This implication is important for empirical studies in implied volatilities because an explicit model of how information flows rationally affect volatility estimates is provided. Furthermore, the equilibrium obtained and the implications of the model are tested empirically in this study.

The unconditional expectation and variance of volatility are defined as $\sigma^{* \star}$ and $\Phi^{2}$, respectively. Hence,

$$
\sigma^{* *}=\delta \bar{\sigma}+(1-\delta) \underline{\sigma} \text { and } \Phi^{2}=\delta(1-\delta)(\bar{\sigma}-\underline{\sigma})^{2} .
$$

If the appropriate conditional probabilities are calculated in a Bayesian manner, the initial ask and bid implied volatilities are given by

$$
a=e^{-r}\left(\sigma^{* *}+\frac{\Phi^{2}}{(\bar{\sigma}-\underline{\sigma})}\left[\frac{\alpha+1 / 3 \beta}{1 / 2(1-\alpha)+\delta \alpha-1 / 3 \beta(1-\delta)}\right]\right)
$$

and 


$$
b=e^{-r}\left(\sigma^{* *}-\frac{\Phi^{2}}{(\bar{\sigma}-\underline{\sigma})}\left[\frac{\alpha-1 / 3 \beta}{1 / 2(1-\alpha)+(1-\delta) \alpha-1 / 3 \beta(1-\delta)}\right]\right) .
$$

This next finding is central to the empirical tests of this study and is obtained by differentiating the bid-ask spread, or the difference between the volatilities on the ask and bid side.

Proposition: For fixed $\alpha$, the volatility spread is a strictly decreasing function of the level of underlying price-contingent-based trading (or $\mu$-trading). More formally,

$$
\frac{\partial[a-b]}{\partial(\delta \beta)}<0 .
$$

The spread (in the absence of brokerage costs) is an inverse measure of market liquidity: The higher the spread, the less liquid the market. The finding just discussed implies that the market in which $\mu$-traders cluster is more liquid than the one in which they do not.

\section{A Microstructure View of the Option Market}

Trading in financial markets involves transaction costs, some of which are exogenous, such as commissions and transaction taxes, and some of which are endogenous, such as the bid-ask spread. The bid-ask spread, defined as the difference between the ask price and the bid price quoted by a market maker, provides the market maker with compensation for the risks inherent in his or her market-making activities. In a market where traders have different information, the market maker faces a severe adverse-selection problem: Because the identity of incoming orders is unknown, the market maker sets a spread to compensate for the loss that could occur from trading with a better-informed trader.

In option markets, the information flow incorporates data about the price (or expected return) and the volatility of the underlying asset. As such, the bid-ask spread in the option market reflects both information components.

In practice, these bid and ask prices are used to calculate implied volatilities by solving for the volatility that sets the option market price equal to the Black-ScholesMerton value. Hence, the option market maker quotes bid and ask implied volatilities and adjusts them as volatility-related information changes.

Bid-Ask Spreads and Informational Efficiency. The complex adverse-selection problem faced by the option market maker is modeled in two recent papers by Cherian (1996) and Cherian and Jarrow (1996). A summary of their model was previously discussed in the theoretical model section. In Cherian and Jarrow's stylized setting, two types of informed traders interact with the relatively uninformed option market maker. So-called volatility traders have perfect information about volatility but imperfect information about underlying price movements. Hence, they buy (sell) options when their estimate of the true volatility is above (below) the implied volatility obtained from the option's ask (bid) price. So-called directional traders have perfect information about the price movements of the underlying asset but imperfect information about volatility. They buy (sell) options if their estimate of the option's value, given their private information, is above (below) the quoted ask (bid) price.

Unfortunately, option market makers cannot distinguish between volatility and directional traders. Instead, they make inferences about the probability of trading with either group from the observed order flow in the options pit. These inferred probabilities 
are reflected in the market maker's bid- and ask-implied volatilities. Cherian and Jarrow showed how these bid-and ask-implied volatilities are (theoretically) related to the true underlying volatility in the following results:

Result 1: If volatility traders dominate the orderflow, then the bid-and ask-implied volatilities (IVB and IVA, respectively) straddle the unconditional estimate of the true underlying volatility $\left(\sigma^{*}\right)$. Mathematically,

$I V A>\sigma^{*}>I V B$.

Result 2: If directional traders dominate the order flow, the bid-implied volatility $(I V B)$ can exceed the unconditional estimate of the true underlying volatility $\left(\sigma^{*}\right)$. Mathematically,

$I V A>I V B>\sigma^{*}$.

These results can be deduced from the theoretical model section.

Informational Efficiency and Liquidity. In a related paper, Cherian (1996) showed that the presence of traders with different types of information determines not only the position but also the size of the option's bid-ask spread. Specifically, the presence of directional traders is a signal to the market maker that volatility is likely to go up. ${ }^{8}$ Consequently, if the option market maker believes that directional traders are dominating the order flow (whether buying or selling), he or she will react by increasing both the bid- and ask-implied volatilities. Bid-ask spreads will decrease, and market liquidity will improve. ${ }^{9}$

In contrast, if market makers believe that volatility traders are buying, they may infer that volatility is likely to rise and, consequently, they will increase the ask-implied volatility. If they believe that volatility traders are selling, signaling a drop in volatility, then they will lower the bid-implied volatility. Recall that the market maker's bid- (ask-) implied volatilities are actually ex post probability assessments of future volatility that are based on observed public sell (buy) orders. Combining these two results suggests that when volatility traders dominate the order flow, the bid-ask spread will widen and markets will become less liquid. An adverse-selection problem arises because market makers are often unable to distinguish between volatility and directional trades.

Using these insights, we formulate the following testable results:

Result 3: When volatility traders dominate option order flow, the bid-ask spread is directly proportional to option volume.

Result 4: When directional traders dominate option order flow, an inverse relationship exists between volume and the bid-ask spread.

Previous Work on Informational Efficiency in Option Markets. The informational role of option prices is a much debated issue. Earlier literature (Manaster and Rendleman 1982, Bhattacharya 1987, and Anthony 1988) has provided evidence of daily option prices leading the underlying stock prices and has attributed this phenomenon to informed traders' preference for the option market.

More-recent studies that use transaction data found mixed evidence of information trading in option markets. Stephan and Whaley (1990) found that stock price changes lead option price changes, whereas Easley, O'Hara, and Srinivas (1994) reported that op-

\footnotetext{
${ }^{8}$ By definition, directional traders trade in high-volatility markets (see Cherian and Jarrow 1996 and the theoretical model section here).

The bid volatility will increase by more than the ask because the market maker believes that volatility is going up, which implies a smaller spread.
} 
tion volume provides information about future stock prices. Vijh (1990) argued that the option market is not dominated by informed trading. He reported that large option trades-conjectured to be information based-have no price effect in the stock market but cause a widening of the bid-ask spread in the option market. He attributed these results to microstructure effects. Kumar, Sarin, and Shastri (1992) found evidence of intermarket front running in the option market but report that following large stock trades, option prices need more time to reach their new equilibrium values than stock prices do.

Our empirical study differs from those just mentioned in that it tries to detect the different reaction of option prices to information about prices and information about volatility. For example, one could argue that the large trades studied by Vijh did not originate from directional traders but from volatility traders. This explanation is consistent with the absence of a price effect (there is no new information about future prices) and the occurrence of a wide bid-ask spread (there is news about future volatility).

\section{Empirical Analysis}

Our empirical tests of information trading in the option markets center around two key questions:

- Does a systematic bias exist in implied-volatility estimates of the true underlying volatility, and can this bias be attributed to the types of traders present in the market (Results 1 and 2)?

- Is market liquidity affected by the type of traders in the market, and does evidence of adverse selection in the option market exist (Results 3 and 4)?

In order to address these issues, we first needed to develop a methodology to distinguish between directional and volatility traders in the data.

Data. Our data consist of time-stamped quotes, traded prices, and volume for IBM stock and its CBOE-traded options during June 1993. For our empirical analysis, we retained only at-the-money call options that are not part of a combined strategy (e.g., a straddle). As outlined earlier, this approach produces a data series with implied volatilities that are rational forecasts of true volatility (i.e., free of biases). Furthermore, we retained the whole range of maturities because we were interested in the implied volatilities for different maturity options. With these constraints, we were able to obtain a trade sample with 5,999 option trade prices and associated sizes and a quote sample with 9,238 bid and ask quotes (no sizes). We also used trade prices and sizes for the underlying stock.

With the quote data, we computed implied volatilities for the trade price and the bid and ask quotes using the dividend-adjusted Black-Scholes-Merton model ${ }^{10}$ Finally, we created a one-minute grid by retaining the last price or quote for each one-minute interval and by summing the volume over this interval. ${ }^{11}$

Identification Tests. Distinguishing between volatility and directional trades turned out be a more daunting task than we envisioned. We are not entirely sure at this stage whether or not our methodology precisely distinguishes between the two trades.

\footnotetext{
${ }^{10}$ Strictly speaking, equity options are American style, thus requiring an American option-pricing formula, such as the quadratic approximation method of Barone-Adesi and Whaley (1987). But because the early exercise premium is small and the Barone-Adesi and Whaley model results in a systematically smaller implied volatility than the Black-Scholes-Merton model, our inferences from the data will not change dramatically.

${ }^{11}$ Consequently, our data is sampled at fixed intervals, a necessary condition for some parts of our statistical analysis. A one-minute grid was chosen to limit information loss to a minimum. Minute data are used in Table 3 .
} 
In any case, we used the following empirical procedure: First, we looked at large option trades because one can assume that such trades originate from informed parties. Second, we analyzed stock market data in the next 15 minutes to look for any abnormal volume patterns (to be defined later).

In constructing these identification tests, we used the insights developed by Easley et al. (1994), who showed that option market volume frequently leads stock prices because the option market is often the first venue for informed traders. Our purpose was to further refine the classification scheme in order to distinguish between price and volatility information. Although crude, our methodology provided a first-order approximation of informational partitioning based on direction and volatility of asset prices.

Specifically, if option trades are based on price information (i.e., they originate from directional traders), then we would expect stock and option prices to change as new information is revealed about the underlying asset. Consequently, we would expect to see large stock market trading volume following only option trades submitted by directional traders, because stock market traders would be eager to exploit the newly available information and/or because the new equilibrium prices in stocks would induce certain traders to revise their hedge ratios.

Conversely, we would not expect such changes to occur if the only information in the market was volatility related, because nothing new would be learned from that information about the stock's fundamental value. Therefore, a large volatility trade in the option market should not lead to large changes in volume because stock market traders have no reason to revise their expectations.

More precisely, we looked at a 15-minute interval starting with a large option trade (larger than or equal to 50 contracts) and recorded it as a directional trade if we found stock volume larger than or equal to 10,000 shares during that interval. If we observed no large stock trade, then we classified the large option trade as a volatility trade. ${ }^{12}$

To summarize, we classified a large option trade followed by large stock market volume as a directional trade. Conversely, we classified a large option trade that did not result in any noticeable stock market volume movements as a volatility trade.

An Outline of Our Empirical Tests. We then conducted three sets of tests that will be described in the next section. In each test, we were interested in the informational content of large option trades. As explained previously, we labeled these large option trades as either directional or volatility. Our objective was to investigate whether these trades lead to significant differences in the behavior of market makers. If market makers are able to distinguish between these two types of trades, then they should, as our theory predicts, be able to adjust their bid and ask quotes accordingly to protect against adverse-selection risk, that is, the risk of trading with a better-informed party. If, in contrast, market makers are unable to recognize the differently informed trades, then directional and volatility trades will not lead to significantly different quote behavior and market makers will be exposed to adverse-selection risk.

\footnotetext{
${ }^{12} \mathrm{~A}$ second identification test, not reported here but available upon request, looked at a window 520 minutes after the large option trade occurred. The idea was that option traders may use the first few minutes (artificially set at 5 minutes in our test) to delta hedge their option positions in the stock market. Therefore, heavy stock market trading in the first 5 minutes following the option trade can be ignored because the trades are not information related. Although more favorable results (i.e., ones that support the hypothesis of the theoretical model) can be obtained by using this test, it does not significantly alter our overall results.
} 
Table 2. Summary Statistics

\begin{tabular}{lcc}
\hline Category & Number of Trades & Number of Quotes \\
\hline A. Market activity & 5,969 & \\
All options & 4,299 & 9,238 \\
Short-term & 1,670 & 5,898 \\
Medium-term & 0 & 3,340 \\
Long-term & Average (Standard Deviation) & 0 \\
& $16(37)$ & Max (Min) \\
All options & $17(41)$ & $2,501(1)$ \\
Short-term & $11(23)$ & $2,501(1)$ \\
Medium-term & & $630(1)$ \\
B. Bid-ask spreads & Price Spread & \\
& $\$ 0.110$ & $I V-S p r e a d$ \\
All options & 0.108 & 0.144 \\
Short-term & 0.124 & 0.168 \\
Medium-term & & 0.103 \\
\hline
\end{tabular}

Note: This table reports summary statistics for the entire sample of transaction data (prices and quotes). Short-term refers to options with up to a three-month maturity remaining; medium-term and long-term refer to three-to-six and six-to-nine month maturities, respectively. The spreads in Panel $B$ are computed as follows:

Price spread $=$ Quoted ask price - Quoted bid price

$I V$-spread $=$ Implied ask volatility - Implied bid volatility

The implied volatilities were calculated from the quoted ask and bid prices, respectively, using a dividend-adjusted BlackScholes-Merton model.

\section{Results}

Before testing the empirical implications of the theoretical model, we looked at the liquidity characteristics of the market as shown in Table 2. As expected, a majority of quotes and trades are in short-term options (one to three months). Average trade sizes are large, which may indicate that most informed traders are in front-end maturities. Option bid-ask price spreads are low, but implied bid-ask volatility spreads are high. This differential may indicate that information asymmetries regarding future volatilities are more pronounced in short-term contracts. Market makers possibly do not worry much about information asymmetries concerning future price movements and thus demand low compensation in the form of a bid-ask spread. The tests in the following sections investigate this issue in greater detail.

As outlined earlier, previous empirical studies have focused mainly on the price effect of informational trading without distinguishing between directional and volatility traders. As a first test, we repeated a price-effect test related to the one done by Vijh (1990). We looked at a sequence of absolute values of percentage changes in stock prices 15 minutes after a large option trade was observed. The statistic we used was

$$
S(t)=\frac{|P(t)-P(0)|}{P(0)},
$$

where $P(t)$ is the stock price $t$ minutes after a large option trade and $P(0)$ is the stock price just before the large option trade takes place. The idea is that if large option trades are motivated by directional traders, the stock market may experience an effect. In contrast, large volatility trades are expected to signal information only about future volatilities. One would thus not expect to see any immediate reaction in the stock market. The three main differences between the Vijh test and our test are as follows:

- The Vijh sample contained only large option trades equivalent to at least 250 round lots of stock (as measured by delta), whereas we used 50 option contracts as the 
criterion for inclusion.

- Vijh partitioned his data set and tested according to stock price increases and decreases, whereas we used absolute percentage changes in stock prices.

- We refined the informational trading test by distinguishing between directional and volatility trading, whereas Vijh did not.

As Table 3 shows, volatility trades, as expected, were not significantly different from zero. Although a similar pattern was observed in directional trades for almost all the minute intervals, directional trades have a more profound effect on stock price changes than volatility trades have. Furthermore, the effect of directional trades on stock price changes appears to grow consistently over time.

Consequently, this first test detected the desired price effect that results from information trading, with directional trading having a greater effect on subsequent stock price changes than volatility trading has. The results obtained here are different from those in Vijh, who found that stock prices are unaffected by large option trades. Our

\section{Table 3. Price Test}

\begin{tabular}{lcc}
\hline Stock Price Ratio $t$ Minutes & Directional Trades & Volatility Trades \\
\hline after Large Option Trade & 0.000670 & 0.000621 \\
& $(0.571107)$ & $(0.526830)$ \\
2 & 0.000887 & 0.000770 \\
& $(0.693245)$ & $(0.635366)$ \\
3 & 0.001025 & 0.001301 \\
& $(0.735830)$ & $(0.290585)$ \\
4 & 0.002762 & 0.001155 \\
& $(0.948973)$ & $(0.852193)$ \\
5 & 0.001583 & 0.001365 \\
& $(0.965747)$ & $(0.910079)$ \\
6 & 0.001667 & 0.001524 \\
& $(1.064434)$ & $(0.918522)$ \\
7 & 0.001991 & 0.001606 \\
& $(0.733304)$ & $(1.082848)$ \\
8 & 0.002091 & 0.001726 \\
& $(1.183518)$ & $(0.983086)$ \\
9 & 0.002032 & 0.001664 \\
& $(1.102833)$ & $(0.983254)$ \\
10 & 0.002125 & 0.001709 \\
& $(1.156487)$ & $(1.114677)$ \\
11 & 0.002126 & 0.001577 \\
& $(1.143276)$ & $(0.992059)$ \\
12 & 0.002221 & 0.001750 \\
& $(1.147212)$ & $(1.042030)$ \\
13 & 0.002420 & 0.001951 \\
& $(1.187743)$ & $(1.096773)$ \\
14 & 0.002544 & 0.002007 \\
& $(1.167946)$ & $(0.742631)$ \\
& 0.002798 & 0.001966 \\
& $(1.025036)$ & $(1.075149)$ \\
\hline
\end{tabular}

Note: This table reports price ratios $S(t)=\mid P(t)-P(0) V P(0)$, where $P(t)$ is the stock price $t$ minutes after a large option trade and $P(0)$ is the stock price just before the large option trade takes place, with the $t$-statistics in parentheses. If $S(t)$ is significantly greater than zero, then the large option trade has a significant price impact on the underlying market and is said to be motivated by superior information. This test is a variant of the one found in Vijh (1990). We executed this test for volatility and directional trades separately, using minute data (obtained by retaining the last price for each one-minute interval; if no trade took place during a particular interval, the last recorded price was used). 
refinement of the Vijh test, based on the theory provided by the Cherian and Jarrow (1996) and Cherian (1996) models, may partially explain the differences in results. "Aggregating" volatility and directional trades as in Vijh may tend to confound the results. Hence, based on the current results, one can reasonably conclude that option trades are motivated by superior information about subsequent stock price movements, with option volatility trades having a smaller effect on stock price changes than option directional trades have.

Bid-Ask Spreads and Informational Efficiency: Sign Tests. To test the relationship between market makers' implied volatility quotes, based on current observed order flow and the perceived identity of traders on the one hand and the true underlying volatility on the other hand, we tested the following hypotheses:

Hypothesis 1: If volatility traders dominate the order flow, then $I V A>H V>I V B$.

Hypothesis 2: If directional traders dominate the order flow, then $I V A>I V B>H V$, where the historical volatility $H V$ is used as a proxy for the unobservable $\sigma^{\star} .{ }^{13}$ These two hypotheses about the relationship between $I V A, I V B$, and $H V$ have the implicit assumption that

$$
I V A=I V B=H V
$$

before any informed trades take place.

Because we found that $H V$ lies between $I V A$ and $I V B$ for most of the non-information-trading time, we modified the two hypotheses to the following:

Modified Hypothesis 1: If volatility traders dominate the order flow, then the implied bid-ask spread will widen.

Modified Hypothesis 2: If directional traders dominate the order flow, then the implied bid-ask spread will narrow.

Formally, we defined the first-order implied bid-ask spread as

$$
\Delta I V_{A-B}(t) \equiv I V_{A-B}(t)-I V_{A-B}(t-1),
$$

where $V_{A-B}(t)$ is the time $t$ implied bid-ask spread (i.e., the difference between the market maker's implied ask and implied bid volatilities, $I V A-I V B), t$ is the time of the informed trade, and $t-1$ is the time of the last trade of the option with the same maturity and strike. Mathematically, the null hypotheses are the following:

For the volatility sample: $\Delta V_{A-B}(t)>0$

For the directional sample: $\Delta V_{A-B}(t)<0$.

We first analyzed the above inequalities for the entire sample of all maturities, and then we repeated our tests for different maturities, shown in Table 4 . When directional traders are perceived to dominate, we found that 59.90 percent of all nonoverlapping directional intervals exhibit the behavior predicted by the modified Hypothesis 2, that is, a narrowing of the spread. Similarly, when we examined volatility intervals, we found that 56.13 percent of all volatility intervals have quotes that conform with the modified first hypothesis, that is, a widening of the spread. When the tests were repeated for different maturities, the predicted patterns in the time profile of the bidask spread seemed to dominate for directional and volatility trading. Medium-term maturities seemed to have results that conform most strongly with the predictions of the modified Hypotheses 1 and 2: 63.89 percent of the medium-term volatility trades lead to a widening of the spread; 76.19 percent of the medium-term directional trades

\footnotetext{
${ }^{13}$ Historical volatility is calculated as the time-varying annualized standard deviation of logarithmic returns over 90 -day windows, using closing prices of the underlying stock.
} 
Table 4. Sign Test

\begin{tabular}{lcc}
\hline & Directional Trades & Volatility Trades \\
\hline $\begin{array}{l}\text { Distribution of informed trades, by maturity } \\
\text { Percentage of informed trades }\end{array}$ & $(n=212)$ & $(n=155)$ \\
$\quad$ belonging to & 80.19 & 76.77 \\
Short-term maturities & 19.81 & 23.23 \\
Medium-term maturities & 0.00 & 0.00 \\
Long-term maturities & & \\
A. All maturities & $(n=212)$ & $(n=155)$ \\
Percentage of first-order implied & 28.30 & 56.13 \\
bid-ask spread difference that is & 59.90 & 30.97 \\
Positive & 11.80 & 12.90 \\
Negative & & \\
No change & $(n=170)$ & $(n=119)$ \\
B. Short-term maturities & 30.59 & 53.78 \\
Percentage of first-order implied & 55.88 & 31.93 \\
bid-ask spread difference that is & 13.53 & 14.29 \\
Positive & & \\
Negative & & $(n=36)$ \\
No change & $(n=42)$ & 63.89 \\
C. Medium-term maturities & 19.05 & 27.78 \\
Percentage of first-order implied & 76.19 & 8.33 \\
bid-ask spread difference that is & 0.476 & \\
Positive & & \\
Negative & &
\end{tabular}

lead to a narrowing of the spread.

In summary, most of the results are consistent with the behavior predicted by the theoretical model of Cherian (1996); that is, if volatility traders dominate the order flow, the implied bid-ask spread widens, and directional trading causes the implied bid-ask spread to narrow. The volatility results are also consistent with the empirical findings of Jameson and Wilhelm (1992), who found that increasing uncertainty about the volatility of the underlying asset tends to widen the bid-ask spread in the corresponding options.

Informational Efficiency and Liquidity: Correlation Tests. To test whether option market makers are able to correctly infer the identity of informed traders from the order flow, we tested the following null hypotheses:

Hypothesis 3: If volatility traders dominate the order flow, then CORR (IV-spread, option volume) $>0$.

Hypothesis 4: If directional traders dominate the order flow, then CORR (IVspread, option volume) $<0$,

where CORR is the correlation coefficient and $I V$-spread is the difference between the market maker's implied ask and bid volatilities.

Because our quote sample did not contain data on option volume and because matching with the trade sample proved to be an impossible task, we used stock volume as a proxy. Furthermore, based on our identification tests discussed earlier, the correlations between option and stock volumes, by construction, were negative for volatility 
samples and positive for directional samples. Hence, the (modified) null hypotheses are as follows:

Modified Hypothesis 3: If volatility traders dominate the order flow, then CORR (IV-spread, stock volume) $<0$.

Modified Hypothesis 4: If directional traders dominate the order flow, then CORR (IV-spread, stock volume) $<0$. follows:

Given the above relationships, we estimate the structural regression equation as

$$
\text { Stock volume }=c+\left(a \times I V_{A-B}\right)+\left(b \times I V_{(A-B) D}\right)+\left(d \times I V_{(A-B) V}\right),
$$

where the $I V$-spread, $I V_{A-B}$, is equal to the difference between the market maker's implied ask and implied bid volatilities $(I V A-I V B), V_{(A-B) D}$ is the $I V$-spread for options from the directional sample, and $V_{(A-B) V}$ is the $I V$-spread for options from the volatility sample. The null hypothesis is that both $b$ and $d$ are negative.

As Table 5 shows, the coefficient for the volatility sample $d$ is significantly negative as predicted. But $b$, the coefficient from the directional sample, is significantly positive. This phenomenon may be caused by various factors, including the fact that we timeaveraged the sample, resulting in upward biases (see "Bid-Ask Spreads and Informational Efficiency: Sign Tests" for one such factor that arises mainly from positive directional intervals having wider bid-ask spreads than the negative directional intervals have).

Table 5. Correlation Test

\begin{tabular}{lcc}
\hline Regression Results & Coefficient & Standard Error \\
\hline$I V_{A-\mathrm{B}}$ & 63,707 & 16,993 \\
$I V_{(A-B) D}$ & 254,003 & 15,272 \\
$V_{(A-B) V}$ & $-91,357$ & 16,239 \\
Constant & 78,447 & 97,161 \\
\hline
\end{tabular}

Note: $R^{2}=0.048599$

\section{Conclusion}

We attempted to verify empirically a theoretical model of the microstructure of option markets. Our main finding was that the presence of volatility traders tends to widen the bid-ask spread in options and the presence of directional traders has the opposite effect. This phenomenon is explained mainly by the fact that the presence of volatility traders is a signal that a subset of the informed traders' assessment of volatility is different from the market's, thus endogenously creating an adverse-selection-type cost reflected through widening spreads. The presence of directional traders has an opposite effect because they create upward biases in volatility, thus diminishing spreads.

Although the theory is quite robust, the empirical tests performed at this stage should be considered only a first step toward developing more-robust tests in subsequent research. Note that segregating the volatility traders from the directional traders for this specific data set was extremely difficult. Furthermore, we had to use stock volume as a proxy for option volume because our quote sample did not contain data on option volume and matching with the trade sample proved an impossible task. Despite these difficulties, results supporting the implications of the model were documented.

As stated in the beginning, academics and practitioners have long been interested 
in the issue of market efficiency. Related to that issue is the study of the actual organization and regulation of financial markets and their effects on informational efficiency. The unprecedented flurry of innovations in both products and information technology has brought to bear the issues of market efficiency and competition between different market systems.

We analyze some of these issues in the context of option markets, which are particularly challenging to practitioners and academics because the information flow incorporates price and volatility data. Most of the microstructure literature, which uses methods developed in the context of equity markets, ignores the volatility component and focuses instead on the price component. In contrast, we provide a way for practitioners to use price and volume data to extract the information content of option prices and make reasonable inferences about market liquidity, concentration of trading in the market, and the market's estimate of future volatility.

Our research also attempts to create a link between the option market microstructure literature and the voluminous literature on implied volatility. The latter literature analyzes the behavior and forecasting ability of implied volatility as calculated from various option-pricing models, among them the Black-Scholes-Merton model. Although some of those studies use transaction prices, their focus is not on the microstructure of option markets. The theoretical microstructure research on option markets rarely models either the presence of volatility traders or the behavior of implied volatility. Similarly, the empirical research typically applies methods developed in the context of primary markets, which do not use implied bid-ask volatilities or the implications therein.

We combine the two approaches by using a theoretical microstructure model of implied volatility. Our tests were designed to verify empirically its validity. The results of our tests are crucial to traders and academic researchers alike because more-powerful tests and specifications can arise only from more-precise economic models of the market's conditional estimate of future volatility. The knowledge from this study will be useful for many aspects of practice, including trading, investing, hedging, and market making.

Finally, our study analyzes the determinants of the option market's liquidity. Researchers commonly believe that a market's liquidity is a function of its microstructure and its information structure. To verify this intuition, we developed statistical tests based on a theoretical model of option market making rather than deriving the tests from primary markets. Needless to say, the mounting importance of derivative markets in general, and option markets in particular, warrants this long-overdue study and its results.

The current theoretical and empirical methodologies can be further refined, and new data sets can be located for more-precise empirical testing. Such investigations await subsequent research.

Given that volatility spreads are increasing in volatility trading and decreasing in directional trading and given that there are upward biases in implied volatilities where directional traders congregate, determining where volatility traders and directional traders are along the term structure of maturities is useful for trading, investing, hedging, and market making. 


\section{References}

Anthony, J.H. 1988. "The Interrelation of Stock and Options Market Trading-Volume Data." Journal of Finance (September):94964.

Azariadis, C. 1981. "Self-Fulfilling Prophecies." Journal of Economic Theory, no. 25:38096.

Back, K. 1993. "Asymmetric Information and Options." Review of Financial Studies, no. 3:435-72.

Barone-Adesi, G., and RE. Whaley. 1987. "Efficient Analytic Approximation of American Option Values." Journal of Finance (June):301-20.

Bhattacharya, M. 1987. "Price Changes of Related Securities: The Case of Call Options and Stocks." Journal of Financial and Quantitative Analysis (March):1-15.

Biais, B., and P. Hillion. 1990. "Option Prices, Insider Trading, and Interdealer Competition." Working Paper, INSEAD.

Black, F. 1971. "Toward a Fully Automated Exchange, Part I." Financial Analysts Journal (July/August):29-34.

Black, F., and M. Scholes. 1973. "The Pricing of Options and Corporate Liabilities." Journal of Political Economy (May/June):637-54.

Canina, L., and S. Figlewski. 1993. "The Informational Content of Implied Volatility." Review of Financial Studies, no. 3:659-81.

Cass, D., and K. Shell. 1983. "Do Sunspots Matter?" Journal of Political Economy (April):193-227.

Cherian, J.A 1993. "Option Pricing, Self-Fulfilling Prophecies, Implied Volatilities, and Strategic Interaction." Unpublished Ph.D. dissertation, Cornell University.

1996. "Discretionary Volatility Trading in Options Markets." Working Paper, Boston University.

Cherian, J.A, and RA Jarrow. 1996. "Options Markets, Self-Fulfilling Prophecies, and Implied Volatilities." Working Paper, Boston University and Cornell University.

The Research Foundation of the ICFA
Cherian, J.A., and E. Perotti. 1996. “Asset Pricing under Political Risk: Theory and Evidence from Hong Kong Stock Options." Working Paper, Boston University and University of Amsterdam.

Easley, D.A., and M. O'Hara. 1987. "Price, Trade Size, and Information in Securities Markets." Journal of Financial Economics (September):69-90.

Easley, D.A., M. O'Hara, and P.S. Srinivas. 1994. "Option Volume and Stock Prices: Evidence on Where Informed Traders Trade." Working Paper, Cornell University.

Eisenberg, L., and RA Jarrow. 1994. "Option Pricing with Random Volatilities in Complete Markets." Review of Quantitative Finance and Accounting, no. 1:5-17.

Feinstein, S. 1995. "The Black-Scholes Formula Is Nearly Linear in $\sigma$ for At-the-Money Options; Therefore Implied Volatilities from At-the-Money Options Are Virtually Unbiased." Working Paper, Boston University.

Glosten, L.R., and P.R. Milgrom. 1985. "Bid, Ask, and Transaction Prices in a Specialist Market with Heterogenously Informed Traders." Journal of Financial Economics (March):71-100.

Hull, J., and A. White. 1987. "The Pricing of Options on Assets with Stochastic Volatilities." Journal of Finance (June) :281-300.

Jameson, M., and W. Wilhelm. 1992. "Market Making in the Options Markets and the Costs of Discrete Hedge Rebalancing." Journal of Finance (June):765-79.

Jarrow, R.A., and S.M. Turnbull. 1996. Derivative Securities. Cincinnati, $\mathrm{OH}$ : SouthWestern College Publishing.

John, K., A Koticha, and M. Subrahmanyam. 1991. "The Micro-Structure of Options Markets: Informed Trading, Liquidity, Volatility, and Efficiency." Working Paper, New York University.

Kumar, R, A Sarin, and K Shastri. 1992. "The Behavior of Option Price around Large Block Transactions in the Underlying Security." Journal of Finance (July):879-89. 
Kyle, A.S. 1985. "Continuous Auctions and Insider Trading." Econometrica (November):1315-35.

Lamoureux, C.G., and W.D. Lastrapes. 1993. "Forecasting Stock Return Variances: Toward an Understanding of Stochastic Implied Volatilities." Review of Financial Studies, no. 2:405-34.

Manaster, S., and R.J. Rendleman, Jr. 1982. "Option Prices as Predictors of Equilibrium Stock Prices." Journal of Finance (September):1043-57.

Merton, R.C. 1973. "Theory of Rational Option Pricing." Bell Journal of Economics and Management Science (Spring):141-83.

O'Hara, M. 1995. Market Microstructure Theory. Cambridge, MA: Blackwell Publishers.

Rubinstein, M. 1985. "Nonparametric Tests of Alternative Option Pricing Models Using All
Reported Trades and Quotes on the 30 Most Active CBOE Option Classes from August 23, 1976 through August 31, 1978." Journal of Finance (June):455-80.

Shell, K. 1977. "Monnaie et Allocation Intertemporelle." Communication to the Roy-Malinvaud Sèminaire d'Économetrie. Mimeo, Paris (title and abstract in French, text in English).

Stephan, J.A, and R. Whaley. 1990. "Intraday Price Change and Trading Volume Relations in the Stock and Stock Options Markets." Journal of Finance (March):191-220.

Stein, J. 1989. "Overreactions in the Options Market." Journal of Finance (September):1011-23.

Vijh, AM. 1990. "Liquidity of the CBOE Equity Options." Journal of Finance (September):1157-79. 